\title{
HUBUNGAN PERAN TEMAN SEBAYA DENGAN MOTIVASI PELAKSANAAN SADARI DETEKSI DINI KANKER PAYUDARA PADA MAHASISWI
}

\section{THE ROLE OF PEER GROUP THE MOTIVATION OF IMPLEMENTATION OF BREAST DETECTION OF BREAST CANCER IN STUDENT}

\author{
Enur Nurhayati Muchsin \\ Program Studi D3 Keperawatan \\ STIKES Karya Husada Kediri \\ Korespondensi Penulis : enur.nurhayati1969@gmail.com
}

\begin{abstract}
Abstrak
Teman sebaya mempunyai kesamaan berpikir dan terikat bersama menjadikan seseorang lebih dekat dengan teman sebaya akan berpengaruh dalam menjaga kesehatan salah satunya yaitu dengan cara mencegah kanker payudara. Salah satu upaya yang bisa dilakukan untuk mendeteksi adanya kanker payudara ini adalah dengan melakukan SADARI. SADARI dapat dilakukan oleh siapapun termasuk oleh remaja putri, sehingga menjadikan motivasi dari luar dirinya untuk meningkatkan kepadulian terhadap kesehatannya.Tujuan penelitian ini adalah Untuk mengetahui Hubungan Peran Teman Sebaya Dengan Motivasi Pelaksanaan SADARI Deteksi Dini Kanker Payudara Pada Mahasiswi.

Rancangan penelitian dengan metode analitik korelasi dengan metode pendekatan crossectional. Variabel penelitian meliputi dependent Peran Teman Sebaya, dan variabel independet Motivasi Pelaksanaan SADARI. Populasi penelitian adalah seluruh mahasiswi d3 keperawatan STIKES karya Husada Kediri pada tanggal 3 sampai 16 Juni 2020 sebanyak 176 orang.Sampel diambil dengan tehnik purposive sampling dengan kriteria inklusi dan eksklusi yang sudah dientukan oleh peneliti dan besar sampel didapatkan sebanyak 122 orang.Data diambil dengan cara memberikan penjelasan terlebih dahulu kepada responden cara pengisisan kuesioner, instrumen penelitian menggunakan kuesioner. Analisa data dengan cross tabulation dengan uji spearman rho, tingkat kemaknaan $\alpha<0,05$.

Hasil uji dengan rumus rho spearman melalui uji manual yang didapatkan Rho hitung 0,005 dan Rho tabel untuk taraf kesalahan 5\% adalah 0,953 jadi Rho hitung > Rho tabel, $\mathrm{H}_{1}$ diterima, berarti ada Hubungan Peran Teman Sebaya Dengan Motivasi Pelaksanaan SADARI. Seorang remaja perlu memiliki teman sebaya sebagai komunikator dan motivator dalam melaksanakan SADARI yang memberikan motivasi pada seorang remaja dengan menggunakan cara dan bahasa yang mudah dimengerti oleh mereka, untuk dapat dilaksanakan dalam kehidupan sehari-hari.
\end{abstract}

Kata kunci : Peran, Motivasi, Palaksanaan SADARI

\begin{abstract}
Peers have the right to think and bond with peers which will affect in maintaining health, one of it is by preventing breast cancer. One of the means that can be done to monitor breast cancer is to do BSE. BSE can be carried out by organizations including teenagers, thus making motivation from outside of themselves to increase awareness of their health. The purpose of this study was to see the relationship between the role of peers and the motivation for implementing BSE in the Early Detection of Breast Cancer in Students. The research design used the analytical method with a cross-sectional oncoming method. The research variables included the dependent role of peers and independent variables of the motivation of BSE implementation. The study population was all 176 students of STIKES D3 (Diploma) nursing programme STIKES on 3rd June to 16th June 2020. Samples were taken by purposive sampling technique with inclusion and exclusion criteria that have been determined by the researcher and the sample size was 122 people. The data is collected by giving an explanation to the respondent in advance of how to fill out the questionnaire. The
\end{abstract}


research instrument was a questionnaire. Data analysis uses cross tabulation with Spearman rho test, the level of significance $\alpha<0.05$.

The test results with the spearman rho formula through manual tests obtained Rho count 0.005 and Rho table for a 5\% error level is 0.953 then Rho count> Rho table, HI is accepted, meaning there is a relationship between peer roles and the motivation to implement BSE. Teenagers need to have peers as a communicators and motivators in implementing BSE, motivating a teenager by using methods and language that are easy for them to understand, so that it can be implemented in daily life.

Keywords : Role, Motivation, Implementation of SADARI

\section{Pendahuluan}

Teman sebaya atau disebut juga dengan Peer Group merupakan individu yang usianya hampir sama mempunyai kesamaan berpikir, bertindak dan terikat dengan kepentingan bersama (Marsito dkk, 2012). Kesamaan dalam berpikir dan bertindak menjadikan seseorang lebih dekat dengan teman sebaya dari pada orang tua mereka sendiri, seseorang akan menghabiskan lebih dari $40 \%$ waktunya bersama teman sebaya. Banyaknya waktu yang dihabiskan bersama temannya akan memiliki pengaruh peran seseorang terhadap sikap, pembicaraan, minat, penampilan dan perilaku (Accolla.J.R \& Calhoun.J.(2013). Kelompok teman sebaya yang menjadi kelompok rujukan bisa beragam. Kelompok teman sebaya bisa berbentuk karena seprofesi, sehobi, sekelas, sealumni, sekampung, dan sedaerah. Kelompok rujukan bisa pula beragam tergantung rujukan yang berkaitan dengan apa. Misalnya motivasi dan kerja keras yang dirujuk adalah kelompok seprofesi, sedangkan untuk berpolitik misalnya teman sepengajian atau sehobi. (Damsar, 2011).

Peran merupakan serangkaian pola sikap perilaku, nilai dan tujuan yang di harapkan oleh masyarakat yang di hubungkan dengan fungsi individu di dalam kelompok, akan mempengaruhi tindakan seseorang dalam menjaga lingkungan dan kesehatan salah satunya yaitu dengan cara mencegah kanker payudara. Salah satu upaya yang bisa dilakukan untuk mendeteksi adanya kanker payudara ini adalah dengan melakukan pemeriksaan payudara sendiri yang disebut dengan SADARI (Handayani \& Sudarmiati, 2012). Pemeriksaan payudara sendiri sangat penting sebagai langkah awal untuk mengetahui seseorang menderita kanker payudara atau tidak. Faktanya, lebih banyak kanker payudara stadium dini dapat dideteksi dengan cara SADARI (Handayani \& Sudarmiati, 2012).

SADARI bermanfaat bagi para perempuan usia muda karena SADARI merupakan pemeriksaan yang mudah dilakukan sendiri dengan cara memperhatikan perubahan pada payudara oleh diri sendiri secara dini adanya benjolan pada payudara (Astutik, 2017) metode SADARI di gunakan untuk mengurangi angka kejadian dan kasus kematian pada kanker payudara.

Berdasarkan hasil penelitian yang dilakukan oleh Eka Afrima Sari ,dkk (2016) di Universitas Padjajaran Bandung Jawa Barat"Motivasi Mahasiswi Keperawatan Dalam Pemeriksaan Payudara Sendiri Sebagai Deteksi Dini Kanker Payudara". Hasil penelitian menunjukkan bahwa 52.89\% responden memiliki motivasi intrinsik yang rendah, dan $47.11 \%$ responden Sedangkan hasil penelitian responden memiliki motivasi ekstrinsik menunjukkan bahwa 51.24\% responden memiliki motivasi ekstrinsik yang rendah, dan motivasi ekstrinsik yang tinggi $48.76 \%$ dalam pelaksanaan Sadari. Hal ini menunjukkan bahwa mahasiswi keperawatan memiliki motivasi ekstrinsik yang rendah dalam pelaksanaan Sadari.(Sari, Maryati, \& Maria, 2016).

Kurangnya motivasi remaja putri untuk melaksanakan SADARI dipengaruhi oleh berbagai faktor diantaranya adalah kurangnya kesadaran diri seseorang untuk mencari tahu penyebab dan tanda gejala kanker payudara, atau dikarenakan dalam keluarga tidak ada yang menderita kanker payudara. Dan kurangnya keterbukaan suatu masalah dengan teman sebaya dalam melaksankan SADARI mengakibatkan bertambahnya kasus angka kejadian kanker payudara, dengan melaksanakan SADARI sebagai deteksi dini kanker payudara, merupakan langkah awal terdepan dan paling penting dalam pencegahan kanker 
Untuk itu perlu ditumbuhkan motivasi bagi remaja untuk melaksanakan SADARI secara sadar dan sukarela. Motivasi menunjukkan pada proses gerakan, termasuk situasi yang mendorong dan timbul dalam diri individu, serta tingkah laku yang ditimbulkan oleh situasi tersebut dan tujuan atau akhir dan gerakan atau perbuatan (Sunaryo, 2013). Motivasi bisa didapatkan baik dari luar diri remaja tersebut dengan cara memberikan edukasi ataupun dari dalam diri remaja itu sendiri. Motivasi akan dirangsang karena adanya tujuan. Jadi motivasi dalam hal ini sebenarnya merupakan respons dari suatu aksi, yakni tujuan. Motivasi memang muncul dari dalam diri manusia, tetapi kemunculannya karena terangsang/terdorong oleh adanya unsur lain, dalam hal ini adalah tujuan (Sardiman, 2016).

Metode peer group memiliki keefektifan yang lebih tinggi dapat menimbulkan motivasi bagi remaja dibanding metode yang lain. Kelompok teman sebaya juga berguna untuk berbagi pengalaman, saling mendukung, membangun kesadaran dan ide baru untuk melakukan pemeriksaan payudara sendiri (SADARI) karena dengan teman sebaya akan lebih terbuka dibandingkan dengan orang tua dan guru, oleh sebab itu peran teman sebaya memiliki pengaruh besar bagi individu dalam melaksanakan pencegahan kanker payudara dengan cara melaksanakan SADARI.

Peran teman sebaya dengan bahasa yang mudah dimengerti oleh para remaja itu sendiri, dan dibicarakan dalam situasi yang bisa diterima oleh remaja, yang pada akhirnya dapat menimbulkan motivasi didalam diri remaja putri untuk melaksanakan SADARI setiap bulan menjelang menstruasi sebagai bentuk pencegahan atau diteksi dini terhadap penyakit kanker payudara dan dapat menekan kasus Kanker Payudara sebagai penyebab kematian pada wanita setelah kanker serviks

Tenaga Kesehatan berperan penting dalam memberikan informasi mengenai kesehatan reproduksi remaja dan membentuk kelompok kelompok remaja di sekolahsekolah atau di masyarakat, agar dapat diterima remaja sebagai bahan edukasi yang nantinya dapat disebarluaskan kepada seluruh remaja putri khususnya. Penelitian ini bertujuan untuk Mengetahui Hubungan Peran Teman Sebaya Dengan Motivasi Pelaksanaan
SADARI Deteksi Dini Kanker Payudara Pada Mahasiswi.

\section{Metode}

Penelitian ini menggunakan jenis penelitian kuantitatif. Rancangan penelitian menggunakan analitik korelasional untuk mengungkapkan hubungan antar variabel. Hubungan yang dimaksud adalah hubungan fungsional yang berdasarkan teori dan logika berfikir dapat diterima, sehingga korelasi yang dimaksud bukan hanya menghubungkan dua data yang tidak memiliki makna. Korelasi mengacu pada kecenderungan bahwa adnya revisi suatu variabel tertentu, maka akan diikuti oleh variasi variabel lain. Dengan demikian, dalam rancangan penelitiaan korelasional peneliti melibatkan paling tidak dua variabel. Menggunakan metode cross sectional adalah penelitian yang merupakan waktu pengukuran atau observasi data variabel independent dan dependent dinilai secara simultan pada suatu saja, jadi tidak ada tindak lanjut (Nursalam, 2013).

Penelitian ini dilaksanakan di STIKES Karya Husada Kediri, waktu penelitian dilaksanakan pada bulan Juni 2020, Lokasi penelitian adalah Prodi D3 Keperawatan STIKES Karya Husada Kediri, alasan pemilihan lokasi penelitian dikarenakan banyak ditemukanya pembentukan group-g roup kecil pada mahasiswi D3 keperawatan, yang mana group-group tersebut terbentuk bisa dikarenakan sehobi dan sekelas atau yang lainnya, dalam group tersebut mereka merasa nyaman untuk saling bercerita tentang permasalahan yang mereka hadapi dari mulai masalah pribadi sampai masalah kesehatan. Biasanya dalam group tersebut ada seorang leader atau pemimpin. Populasi dalam penelitian ini adalah seluruh mahasiswi D3 Keperawatan STIKES Karya Husada Kediri sebanyak 176 orang..Teknik sampling yang digunakan adalah purposive sanpling sehingga sampel tersebut dapat mewakili karakteristik populasi yang telah dikenal sebelumnya (Nursalam, 2014).

Kriteria penelitian Inklusi yaitu :

1. Mahasiswi yang bersedia dijadikan responden

2. Mahasiswi yang belum menikah

3. Mahasiswi yang tidak hamil/belum pernah melahirkan

4. Mahasiswi yang masuk saat penelitian. 
Kriteria penelitian Eksklusi yaitu:

1. Mahasiswi yang tidak bersedia dijadikan responden

2. Mahasiwa yang menderita tumor jinak kanker payudara

\section{Pengumpulan Data}

Penelitian dimulai dengan, menyerahkan permohonan kesediaan menjadi responden kepada calon responden lalu responden menandatangani lembar persetujuan menjadi responden, memberikan penjelasan terlebih dahulu cara pengisian kuesioner, selanjutnya memberikan waktu untuk mengisi kuesioner yang telah dibagikan, setelah diisi keseluruan pertanyaan kemudian oleh peneliti kuesioner dikumpulkan dan mengecek kuesioner sudah terisi lengkap.

\section{Analisa Data}

Analisa data secara analitik dilakukan dengan menggunakan uji statistik dalam penelitian ini adalah korelasi Rho Spearman untuk mengetahui kuat tidaknya hubungan dua variabel yang tidak berdistribusi.yang signifikan secara statistik menggunakan tingkat kemaknaan $(\alpha) 0.05$ atau $p<0.05$. Hipotesis adalah suatu peryataan asumsi tentang hubungan antara dua atau lebih variabel yang diharapkan bisa menjawab sebuah pertanyaan dalam penelitian.

H1 : Ada Hubungan Peran Teman Sebaya Dengan Motivasi Pelaksanaan SADARI Deteksi Dini Kanker Payudara Pada Mahasiswi

Dengan demikian tingkat kesalahan $5 \%$ bila nilai $\mathrm{t}_{\text {hitung }}$ dari pada $\mathrm{t}_{\text {tabel }}$ maka hipotesa $\left(\mathrm{H}_{1}\right)$ diterima, sebaliknya bila nilai $t_{\text {hitung }}<$ dari $t_{\text {tabel }}$ maka hipotesa $\left(\mathrm{H}_{\mathrm{O}}\right)$ ditolak

Dengan nilai $\alpha=0.05$

1. $\mathrm{H}_{1}$ diterima apabila nilai $t_{\text {hitung }} \geq$ dari $t_{\text {tabel }}$

2. $\mathrm{H}_{\mathrm{O}}$ ditolak apabila nilai $\mathrm{t}_{\text {hitung }}<$ dari $\mathrm{t}_{\text {tabel }}$

\section{Pembahasan}

\section{Karakteristik Responden}

\section{a. Umur}

Distribusi frekuensi responden berdasarkan umur

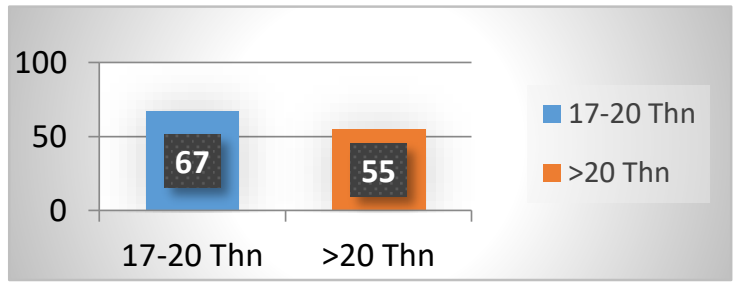

Gambar 1. Diagram Distribusi Frekuensi Berdasarkan Umur di STIKES Karya Husada Kediri Juni 2020.

Berdasarkan Gambar 1 diatas menunjukkan bahwa dari 122 responden, hampir setengah dari responden berumur 17-20 sebanyak 67 responden (55\%), dan sebagian besar responden umur > 20 tahun sebanyak 55 responden $(45 \%)$.

\section{b. Tingkat Perkuliahan}

Distribusi frekuensi responden berdasarkan tingkat

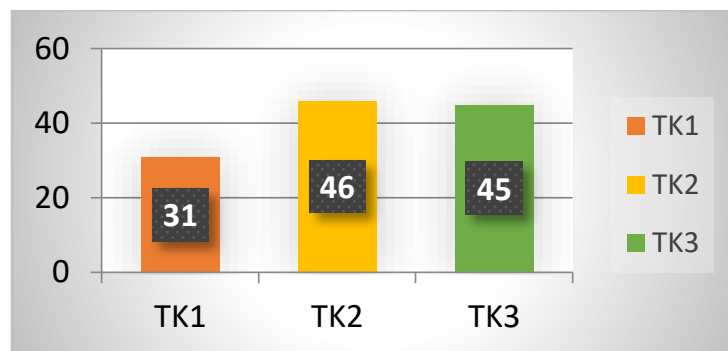

Gambar 2. Diagram Distribusi Frekuensi Berdasarkan Tingkat Perkuliahan STIKES Karya Husada Kediri Juni 2020

Berdasarkan Gambar 2 diatas menunjukkan bahwa dari 122 responden sebagian besar responden yaitu 45 responden (37\%) Tk 3 dan sebagian kecil dari responden yaitu 31 responden (25\%) Keperawatan Tk 1.

\section{c. Tinggal Besama}

Distribusi frekuensi responden berdasarkan tinggal bersama siapa.

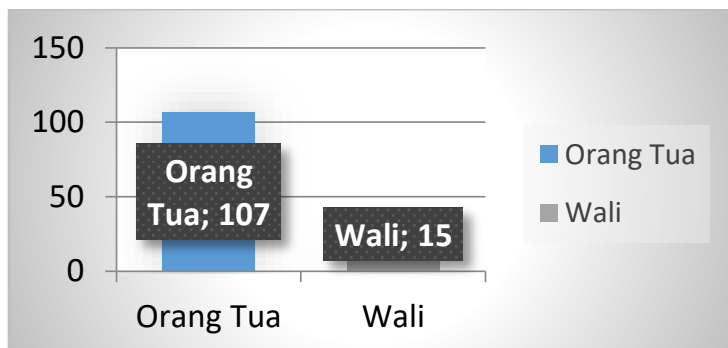

Gambar 3. Diagram Distribusi Frekuensi Berdasarkan Tinggal Bersama Siapa STIKES Karya Husada Kediri tanggal 0316 Juni 2020

Berdasarkan Gambar 3 diatas didapatkan dari 122 responden sebagian besar 107 responden $(88 \%)$ tinggal bersama orang tua dan sebagian kecil 15 responden (12\%) tinggal bersama wali. 
d. Kepemilikan Teman Sebaya

Distribusi frekuensi responden bedasarkan kepemilikan teman sebaya.

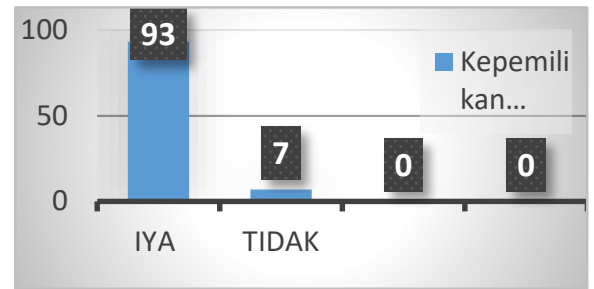

Gambar 4. Diagram Distribusi Responden Berdasarkan Kepemilikan Kelompok Teman Sebaya STIKES Karya Husada Kediri juni 2020.

Berdasarkan Gambar 4 diatas menunjukkan bahwa dari 122 responden, Hampir seluruh responden ya memiliki teman sebaya sebanyak 114 responden (93\%), dan sebagian kecil dari responden tidak memiliki teman sebaya sebanyak 8 responden (7\%).

e. Pernah Melakukan SADARI

Distribusi frekuensi responden berdasarkan pernah melakukan SADARI atau tidak

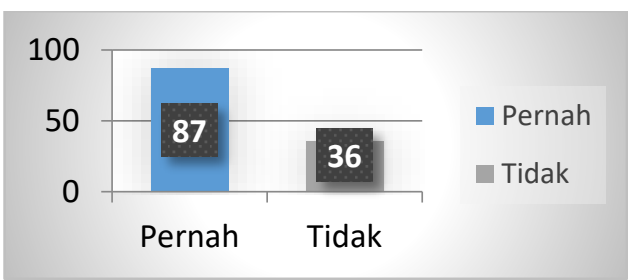

Gambar 5. Diagram Distribusi Frekuensi Responden Berdasarkan Apakah Pernah Melakukan SADARI STIKES Karya Husada Kediri Juni 2020.

Berdasarkan Gambar 5 diatas didapatkan dari 122 responden sebagian besar 87 responden (71\%) pernah melakukan SADARI dan sebagian kecil 36 (29\%) responden tidak pernah melakukan SADARI.

\section{f. Sumber Informasi}

Distribusi frekuensi responden berdasarkan sumber informasi yang didapatkan

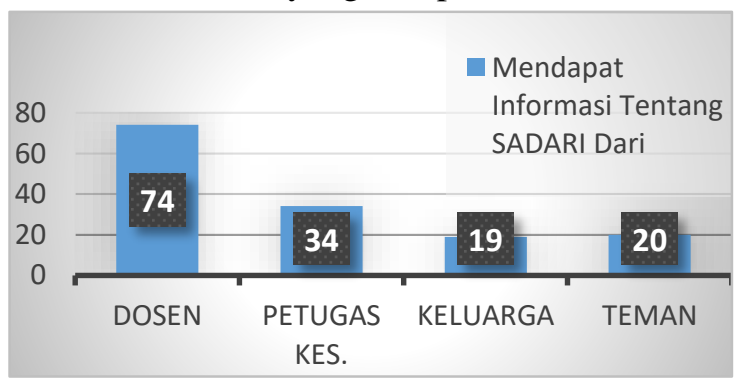

Gambar 6. Diagram Distribusi Frekuensi Berdasarkan Sumber Informasi STIKES Karya Husada Kediri Juni 2020.

Berdasarkan Gambar 6 diatas didapatkan dari 122 responden sebagian besar responden sebanyak 74 responden (50\%) mendapatkan informasi dari dosen, dan sebagian kecil dari responden sebanyak 19 responden (13\%) mendapat informasi dari keluarga.

\section{Data Khusus}

Hasil uji diolah mengguakan SPSS 16.0 dengan rumus Rho spearman didapatkan Rho hitung 0,005 dan Rho tabel untuk taraf kesalahan 5\% adalah 0,953 jadi Rho hitung > Rho tabel, $\mathrm{H}_{1}$ diterima, berarti ada Hubungan Peran Teman Sebaya Dengan Motivasi Pelaksanaan SADARI

\section{Pembahasan}

Peran adalah suatu konsep perihal apa yang dapat dilakukan individu dalam masyarakat sebagai organisasi, peran juga dapat diartikan sebagai perlakuan individu yang penting bagi struktur sosial masyarakat (Soekanto, 2010). Dalam kehidupan seseorang khususnya seorang remaja, pertama kali sebagai kelompok rujukannya adalah keluarga. Seiring berjalannya waktu kelompok teman sebaya (peer group) menjadi kelompok rujukan (reference group) dalam mengembangkan sikap dan perilaku. Sosialisasi melalui kelompok teman sebaya bersifat informan dan langsung.

Peran teman sebaya dalam pelaksaaan SADARI memberikan motivasi pada seorang remaja denga menggunakan cara dan bahasa yang mudah dimengerti oleh mereka, untuk dapat dilaksanakan. Hal ini sesuai dengan hasil penelitian didapatkan bahwa 87 responden $(71 \%)$ sudah melaksanakan SADARI didalam kehidupannya dalam upaya pencegahan kanker payudara.

Sebanyak 114 responden (93\%) memiliki teman sebaya. Menunjukan bahwa teman sebaya perlu di miliki seseorang yang berguna sebagai komunikator dan motivator.Peran teman sebagai motivator tidak kalah penting dari peran lainya, teman harus mampu memberikan motivasi, arahan dan bimbingan di dalam kelompok agar dapat mencapai tujuan yang diinginkan.

Motivasi merupakan perubahan energi dalam diri seseorang yang ditandai dengan 
munculnya "feeling" dan didahului dengan tanggapan terhadap adanya tujuan (Sardiman, 2016). Motivasi memiliki dua komponen, yakni komponen dalam diri seseorang yang bisa dipengaruhi oleh usia dan komponen dari luar diri seseorang yang bisa dipengaruhi oleh tingkat pendidikan, kebiasaan, sumber informasi, dan riwayat keluarga. Timbulnya motivasi dalam diri seseorang akan merasakan sesuatu kebutuhan tertentu pula. Kebutuhan ini timbul oleh karena adanya perubahan (internal change) dalam diri seseorang atau disebabkan oleh perangsang kejadiankejadian di lingkungan seseorang (Hamalik, 2013). Motivasi menunjukkan pada proses gerakan, termasuk situasi yang mendorong dan timbul dalam diri individu, serta tingkah laku yang ditimbulkan oleh situasi tersebut dan tujuan atau akhir dan gerakan atau perbuatan (Sunaryo, 2013). Motivasi memang muncul dari dalam diri manusia, tetapi kemunculannya karena terangsang/terdorong oleh adanya unsur lain, dalam hal ini adalah tujuan (Sardiman, 2016). Menyeleksi perbuatan, yakni menentukan perbuatanperbuatan apa yang harus dikerjakan yang serasi guna mencapai tujuan dengan menyisihkan perbuatan-perbuatan yang tidak bermanfaat bagi tujuan tersebut (Sardiman, 2016). Pelaksanaan SADARI dapat dimulai dari remaja khususnya yang berada pada kelompok teman sebaya akan menggurangi angka kejadian kanker payudara, diharapkan nantinya para remaja akan melaksanakannya didalam kehidupan sehari-hari, khususnya pada saat menjelang menstruasi setiap bulannya.dan menularkan kembali informasi tentang pentingnya pelaksanaan SADARI kepada para remaja lainnya.

\section{Kesimpulan}

Berdasarkan hasil penelitian, analisa data dan pembahasan dapat disimpulkan adanya Hubungan Peran Teman Sebaya Dengan Motivasi Pelaksanaan SADARI deteksi dini kanker payudara pada mahasiswa.

\section{Saran}

Ditujukan kepada tenaga kesehatan dan orang tua, untuk lebih meningkatkan peran teman sebaya di lingkup remaja, agar tersampaikannya informasi mengenai kesehatan reproduksi remaja dengan bahasa yang mudah dimengerti oleh para remaja, melalui pendekatan yang bisa diterima oleh para remaja.

\section{Ucapan Terima Kasih}

Pertama - tama saya ucapkan terima kasih kepada Ketua STIKES Karya Husda Kediri, Ketua Prodi D3 Keperawatan, Responden dalam Penelitian dan Jurnal Ilmiah Pamenang yang telah banyak membantu dalam proses pelaksanakan penelitian sampai dengan publikasi hasil penelitian.

\section{Daftar Pustaka}

Acocella, J. R., \& Calhoun, J. (2013). Psychology of Adjustment and Human Relations. McGraw-Hill.

Astutik. (2017). Asuhan Ibu dalam Masa Kehamilan. Erlangga.

Damsar. (2011). Pengantar Sosiologi Pendidikan. Kencana.

Hamalik, O. (2013). Proses Belajar Mengajar. PT.Bumi Aksara.

Handayani, S., \& Sudarmiati, S. (2012). Pengetahuan Remaja Putri Tentang Cara Melakukan Sadari. Diponegoro Journal of Nursing, 1(1), 93-100.

Marsito, Reza, F., \& Saraswati, R. (2012). Efektifitas Penyuluhan Kesehatan Oleh Peer Group Dan Tenaga Kesehatan Tentang Perilaku Hidup Bersih Sehat (PHBS) Cuci Tangan Bersih Pada Siswa Sd N 01 Dan 02 Bonosari Sempor Kebumen. Jurnal Ilmiah Kesehatan Keperawatan, 8(1), 1-6.

Nursalam. (2013). Konsep dan Penerapan Metodelogi Penelitian Ilmu Keperawatan,Instrumen penelitian Keperawatan Skripsi,Tesis dan Disertasi. Salemba Medika.

Nursalam. (2014). Metodologi Penelitian Ilmu Keperawatan Pendekatan Praktis. Salemba Medika.

Sardiman. (2016). Interaksi Motivasi Belajar dan Mengajar. Raja Grafindo Persada.

Sari, E. A., Maryati, I., \& Komariah, M. (2016). Motivasi Mahasiswi Keperawatan Dalam Pemeriksaan Payudara Sendiri Sebagai Deteksi Dini Kanker Payudara. Jurnal Ilmu Keperawatan, 4(1).

Soekanto, S. (2010). Sosiologi Suatu Pengantar. Rajawali Pers.

Sunaryo. (2013). Psikologi Untuk Keperawatan. Egc. 